\title{
Effect of Curing Environment on the Strength Properties of Cement and Cement Extenders
}

\author{
Mark Bediako1* ${ }^{*}$, J. T. Kevern², Eric Opoku Amankwah ${ }^{3}$ \\ ${ }^{1}$ Council for Scientific and Industrial Research, Building and Road Research Institute, Materials Engineering \\ Development Division, Kumasi, Ghana \\ ${ }^{2}$ Department of Civil and Mechanical Engineering, University of Missouri, Kansas City, Missouri, USA \\ ${ }^{3}$ Development Office, University of Education-Winneba, Kumasi Campus, Kumasi, Ghana \\ Email: "b23mark@yahoo.com
}

Received 21 October 2014; revised 18 November 2014; accepted 6 December 2014

Copyright (C) 2015 by authors and Scientific Research Publishing Inc.

This work is licensed under the Creative Commons Attribution International License (CC BY).

http://creativecommons.org/licenses/by/4.0/

(c) (i) Open Access

\section{Abstract}

Curing of cement based products such as concrete and mortar, is very important to achieve good strength and durable products. However the curing environment plays a pivotal role in the overall quality of cement based products in terms of strength development. ASTM C192 allows moist curing either in a fog room or under water. However, these must meet ASTM C511 which controls temperature, and specifically for water curing, the concentration of calcium ions in the curing solution. Unfortunately in many parts of the world, water curing literally means curing in tap water. This is done primarily because there is a lack of knowledge or ignorance regarding the mobility and roll of calcium hydroxide in the curing process. To illustrate the differences, in this study, straight ASTM Type I/II Portland cement and that mixed with powdered waste clay bricks as a cement extender were used to prepare two different batches of mortars. The chemical properties of the powdered waste clay brick met the ASTM C618 standard specifications for Class N pozzolans. Both mortar specimens were cured under two different environment comprising of either water and lime saturated water. Mortar specimens were tested for compressive strength at 3, 7, 14 and 28 days of either curing conditions. Test results indicated that mortar specimens cured in lime saturated water obtained higher strength than those cured in fresh water at all ages of curing. Statistical inference drawn from ANOVA testing showed that curing conditions had significant impact on strength development of the blended and unblended cement systems. The study recommends that testing of concrete and mortar samples and other research related works be performed in lime saturated water other than fresh water.

\footnotetext{
*Corresponding author.
} 
Keywords

Curing, Water, Lime Saturated Water, Mortar, Compressive Strength, ANOVA

\section{Introduction}

Since the introduction of modern Portland cement by Joseph Aspdin, a British mason, in 1824-the material has undergone series of refinement and now known to be the most commonly utilized binding agent for the formation of concrete and mortar for the global construction industry [1]. Hydraulic cement, also known as Portland cement, has successfully been used for the construction of major structural works including bridges, pavements, dams, high rise building and residential apartment, etc. Many structures constructed from Portland cement sinceits commercialization in Britain many years ago have survived well with little or no maintenance. The construction industry without cement is tantamount to human beings without air. Currently the global demand for Portland cement stands at approximately 5 billion tonnes as of the end of 2013 [2]. In modern construction, Portland cement usage has seen many modifications. Most notably these modifications aim to achieve optimum cement utilization and economy [3]. Materials usually used to modify cements are referred to as supplementary cementitious materials (SCMs) or cement extenders including pozzolanic and hydraulic materials such as fly ash, silica fume, calcined clay and shales, slags and other filler materials such as limestone, chalk, ripple glass, etc. [4] [5]. The use of supplementary cementitious materials or cement extenders have usually been limited to between $20 \%$ and $30 \%$ of cement replacement by many reseachers [6]-[9].

In many structural constructions, strength properties of mortar and concrete are among the most important parameters that best describes the quality and structural durability of a project. In many instances, building professionals are paid and rated depending on the strength quality of mortar or concrete. The achievement of maximum strength is dependent on the extent of cement hydration. With proper curing cement can more fully hydrate and achieve maximum strength. In Ghana, many building professionals depend on laboratory controlled practices to determine the compressive strength of formulated concrete or mortar. A recent survey carried out within building professionals and laboratory technicians showed that about $95 \%$ of concrete and mortar curing is carried out in fresh water [10]. This problem is not peculiar to only Ghana but many other African, Asia and South American nations. However standardized practices in larger economies such as the United States and China perform laboratory curing of concrete and mortar in a lime saturated environment usually in accordance with ASTM C192 [11]. The European standards however are very silent on the type of curing water for concrete cubes [12]. Improper curing or lack of adherence to best standard practices could significantly affect strength properties of concrete and mortar. Though many factors other than curing affect the development of strength, this work focuses on the effect curing environment has on lab-cured specimens. Lower tested strength resulting from improper curing practices skews mixes to higher cementitious material contents which increase not only the cost but embodied $\mathrm{CO}_{2}$. There is the need to reconcile the commonly used Ghanaian, and other African laboratory curing practice to that of the developed countries in order not to compromise and misinformed contractors, consultant and owners on the strength properties of cement based products.

In this study the main objective was to investigate the effect different curing environment or medium, fresh water and lime saturated water has on the compressive strength of cement based products. In order to prevent the variability that results from aggregates using concrete, the study scope focused mainly on mortars formulated from cement and an extender comprising of a powdered waste clay brick. The hypotheses for the study were:

1) Does water curing environment affect the compressive strength of Portland cement?

2) Does water curing environment affect the compressive strength of Portland cement blended binder more than straight Portland cement?

\section{Literature Review}

Curing is the maintenance of satisfactory moisture content and temperature in concrete or mortar for a sufficient period of time immediately following placement [13]. Curing has a strong influence on hardened cement products (mortar and concrete) by improving strength, volume stability, permeability resistance and durability [14]. The methods used for curing involves those that maintain availability of water such as ponding or immersion, 
sprinkling or fogging and covering concrete surface with wet burlap and those that minimize loss of mixing water from concrete including membrane forming compounds, impervious paper or plastic sheets [14]. The importance of these two methods of curing is primarily to help cement achieve more complete hydration.

Cement hydration leads to the formation of cement compounds including calcium silicate hydrate (CSH), portlandite (CH), and ettringite (Aft) [15]. Neville [16] has pointed out that when the relative humidity in a mix falls below $80 \%$, curing ceases. Curing performed in a suitable environment especially at early stages of hardening produces good concrete and mortars because cement becomes fully hydrated. At early ages, $\mathrm{CH}$ is an important compound which accelerates cement hydration whilst at later age it contributes to pozzolanic reaction. Low concentrations of $\mathrm{Ca}^{2+}$ especially at early hydration stage produces low pozzolanic reactivity hence decreases compressive strength. $\mathrm{CH}$ is relatively mobile in the cement paste matrix and can easily be leached out. Dissolution and leaching of $\mathrm{CH}$ increases the porosity within the cement system and decrease the $\mathrm{pH}$ level which consequently compromise strength and durability of cement based products [17] [18]. The $\mathrm{pH}$ level in cement and cement extenders during hydration and pozzolanic reaction is very vital for the dissolution of pozzolanic materials and reformation of additional CSH. In circumstances where improper curing contributes to leaching of $\mathrm{CH}$, there is usually a reduction in compressive strength of concrete or mortar.

Curing of specimens in the laboratory is usually different from concrete placed during construction. The ASTM specification has developed standards for each, ASTM C192 [11] and ASTM C31 [19]. The ASTM C192 [11] isutilized for laboratory curing whereas the ASTM C31 [19] is used for field samples. Zemajtis [20] mentions that variations in standard curing of test specimen can dramatically affect measured concrete properties. However, this basic knowledge is not commonly understood in many developing countries and may result in over-cemented mixtures.

\section{Materials and Methods}

\subsection{Materials}

The materials used for the study were ASTM Type I/II cement, powdered waste clay brick (PWCB), calcium hydroxide, potable water, polycarboxylated high-range water reducer, and sand. The cement was Ashgrove from Chanute, Kansas City, Missouri. PWCB was obtained from Council for Scientific and Industrial Research-BRRI brick factory in Ashanti Region, Ghana. The sand used for the study was a graded silica sand and conformed to the ASTM C778 [21]. The water reducer was BASF Glenium 7500. Table 1 presents the physical and chemical properties of the ASTM Type I cement and PWCB. The PWCB contains main oxides, $\mathrm{SiO}_{2}, \mathrm{Al}_{2} \mathrm{O}_{3}$ and $\mathrm{Fe}_{2} \mathrm{O}_{3}$ at 89.9\% satisfying the ASTM class N pozzolan recommended in the ASTM C618 standard specifications [22].

\begin{tabular}{|c|c|c|}
\hline Property & ASTM Type I/II & PWCB \\
\hline \multicolumn{3}{|l|}{ Physical } \\
\hline Fineness $\left(\mathrm{m}^{2} / \mathrm{kg}\right)$ & 401.7 & 410.5 \\
\hline specific gravity & 3.13 & 2.45 \\
\hline \multicolumn{3}{|l|}{ Chemical } \\
\hline $\mathrm{SiO}_{2}(\%)$ & 20.49 & 67.35 \\
\hline $\mathrm{Al}_{2} \mathrm{O}_{3}(\%)$ & 4.26 & 14.70 \\
\hline $\mathrm{Fe}_{2} \mathrm{O}_{3}(\%)$ & 3.14 & 7.83 \\
\hline $\mathrm{CaO}(\%)$ & 63.48 & 2.19 \\
\hline MgO (\%) & 2.11 & 1.67 \\
\hline $\mathrm{SO}_{3}(\%)$ & 2.9 & 0.15 \\
\hline $\mathrm{Na}_{2} \mathrm{O}+\mathrm{K}_{2} \mathrm{O}(\%)$ & 0.49 & 1.21 \\
\hline LOI (\%) & 2.2 & 4.01 \\
\hline
\end{tabular}




\subsection{Methods}

\section{Mortar Preparation, Mixing and Curing}

The mortars were prepared in accordance with the ASTM C109 [23]. The method specifies sand to cement ratio of 2.75 while maintaining a water-to-cement ratio at 0.485 . Two batches of mortar specimens were prepared which included those cured in saturated lime water and those cured in fresh water. PWCB was pulverized to 75 microns and blended with Portland cement to form a binder for another batch of mortar formation. The water reducer (HRWR), Glenium 7500 was added to mortar mix containing PWCB to maintain a flow between 105 and $115 \%$ as determined by ASTM C1437 [24]. Addition of 30\% PWCB to 70\% of cement produced a stiffer mix hence the need for a superplasticizer to improve workability of the mortar mix. Table 2 shows the mortar mixture proportion of the control (CONT) and the Portland cement blend containing 30\% waste clay brick powder (PWCB). The mixture proportions were used to prepare six mortar specimen per batch. Specimens were cast in $50 \mathrm{~mm}$ cubic metallic molds and allowed to set for $24 \mathrm{hrs}$ at a temperature of $23^{\circ} \mathrm{C}$, covered with a plastic sheet and a wet burlap to prevent evaporation. The specimens were demolded after 24 hrs and samples cured in two separate environments of fresh water and lime saturated water for 3, 7, 14 and 28 days. Compressive strength is reported on an average of three samples.

Inferential statistical analysis was performed using analysis of variance (ANOVA) on the two separate batches of mortars cured under the two different environment for 3, 7, 14 and 28 days. The hypothesis made for the ANOVA test was as follows:

$$
\begin{array}{ll}
\text { Ho: } & \mu_{1}=\mu_{2}=\mu_{3}=\mu_{4} \\
\text { Ha: } & \mu_{1} \neq \mu_{2} \neq \mu_{3} \neq \mu_{4}
\end{array}
$$

where Ho and Ha represent the hypothesis and alternative hypothesis whereas $\mu_{1}$ and $\mu_{2}$ represent the mean values of water and lime curing respectively. The ANOVA test was performed at a 95\% confidence level.

\section{Results and Discussions}

Table 3 presents the compressive strength of the control (CONT) and Portland blended cement labeled as PWCB cured in water and lime saturated water. All mortar specimens cured in lime solution generally acquired greater strength than those cured in water solution at all curing periods. For the control mortars, the percentage increase of lime curing over water curing was between $0 \%$ and $19 \%$ whereas that of PWCB was between $21 \%$ and $66 \%$.

Table 2. Mortar mix proportion.

\begin{tabular}{ccccccc}
\hline \multirow{2}{*}{ Mix name } & \multicolumn{5}{c}{ Mass (g) } & Flow (\%) \\
\cline { 2 - 6 } & Cement & PWCB & Sand & Water & HRWR & \\
\hline CONT & 500 & 0 & 1375 & 243 & 0.0 & 107 \\
PWCB & 350 & 150 & 1375 & 243 & 2.7 & 107 \\
\hline
\end{tabular}

\begin{tabular}{|c|c|c|c|c|c|c|c|c|}
\hline \multirow{3}{*}{ Curing medium } & \multicolumn{4}{|c|}{ CONT } & \multicolumn{4}{|c|}{ PWCB } \\
\hline & \multicolumn{8}{|c|}{ Curing time (days) } \\
\hline & 3 d & $7 \mathrm{~d}$ & $14 d$ & $28 \mathrm{~d}$ & $3 \mathbf{d}$ & $7 \mathrm{~d}$ & $14 d$ & $28 \mathrm{~d}$ \\
\hline Water (MPa) & 27.5 & 32.5 & 33.3 & 36.9 & 24.0 & 29.8 & 31.5 & 38.0 \\
\hline $\mathrm{COV}$ & $5 \%$ & $5 \%$ & $2 \%$ & $5 \%$ & $5 \%$ & $1 \&$ & $1 \%$ & $0 \%$ \\
\hline Lime water (MPa) & 29.4 & 32.5 & 36.4 & 44.0 & 32.6 & 36.0 & 39.7 & 48.1 \\
\hline COV & $6 \%$ & $3 \%$ & $1 \%$ & $0 \%$ & $1 \%$ & $8 \%$ & $1 \%$ & $7 \%$ \\
\hline \% increase & $7 \%$ & $0 \%$ & $9 \%$ & $19 \%$ & $36 \%$ & $21 \%$ & $26 \%$ & $27 \%$ \\
\hline
\end{tabular}

Table 3. Compressive strength of CONT and PWCB in different curing environments.

NB: COV-coefficient of variance. 
Figure 1 and Figure 2 show the curing trend of CONT and PWCB against compressive strength at different curing times. Both figures indicated that strength gain was proportional to curing period irrespective of the curing medium. This is because hydration products that contribute to strength are formed as curing progress.

Table 4 and Table 5 show the ANOVA results for both mortars respectively cured in water and lime saturated water. Table 4 and Table 5 show the ANOVA for CONT and PWCB from Table 3 results. Table 4 gives P-values of approximately 0.14 and 0.04 for the rows and column which represents the curing environment and curing days respectively. From these results, curing environment had no effect on unblended cement mortar at 3 and 7 days. However as strength develops with time there was a statistically significant difference that emerges as a results of the curing conditions. As cement hydration proceeded with time, further dissolution and leaching of $\mathrm{CH}$ occurred in the water curing environment than the lime saturated curing environment. Higher $\mathrm{CH}$ leaching and dissolution increase cement matrix porosity and therefore results in lower strength [25].

Table 5 which shows the ANOVA of Portland blended cement with cement extender and labelled as PWCB had P-values of approximately 0.002 for rows and 0.004 for columns which also represented the curing environment and curing period respectively. The obtained P-values from this study show that both the curing environment and period or days was very significant when it for blended cement. This proves that the addition of

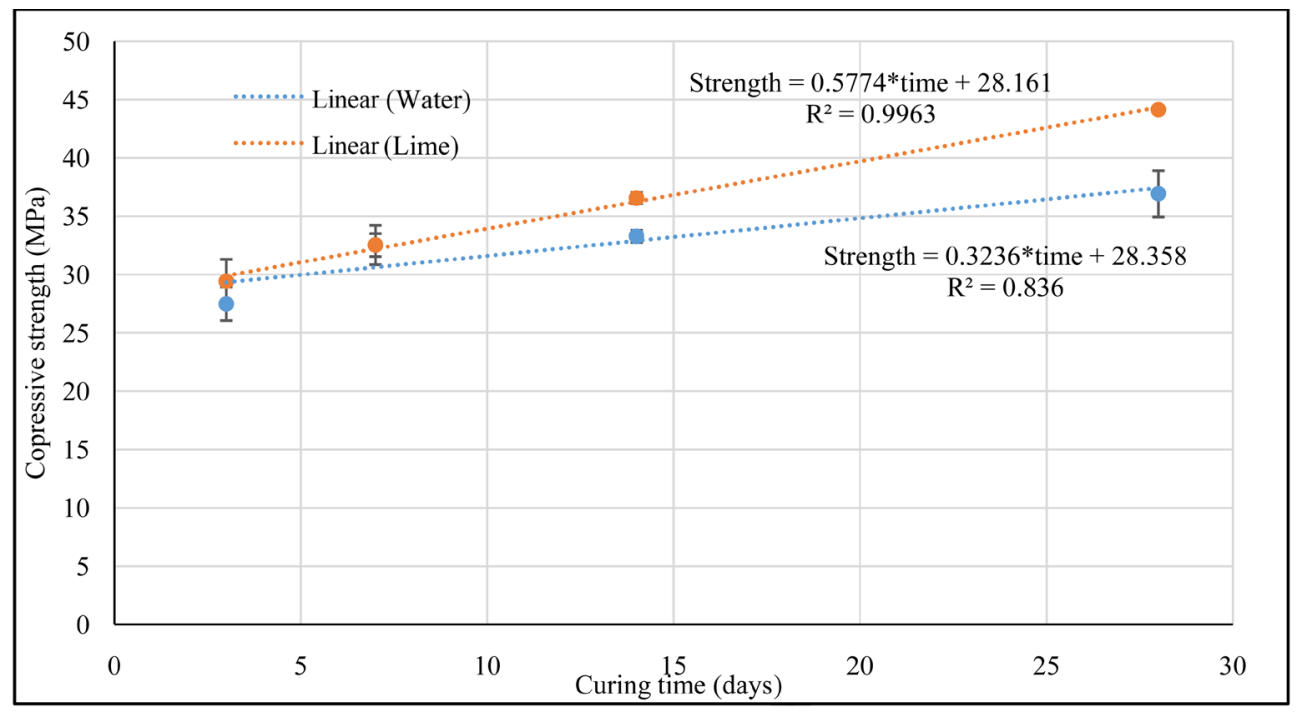

Figure 1. CONT mortar mix cured in fresh and lime saturated water.

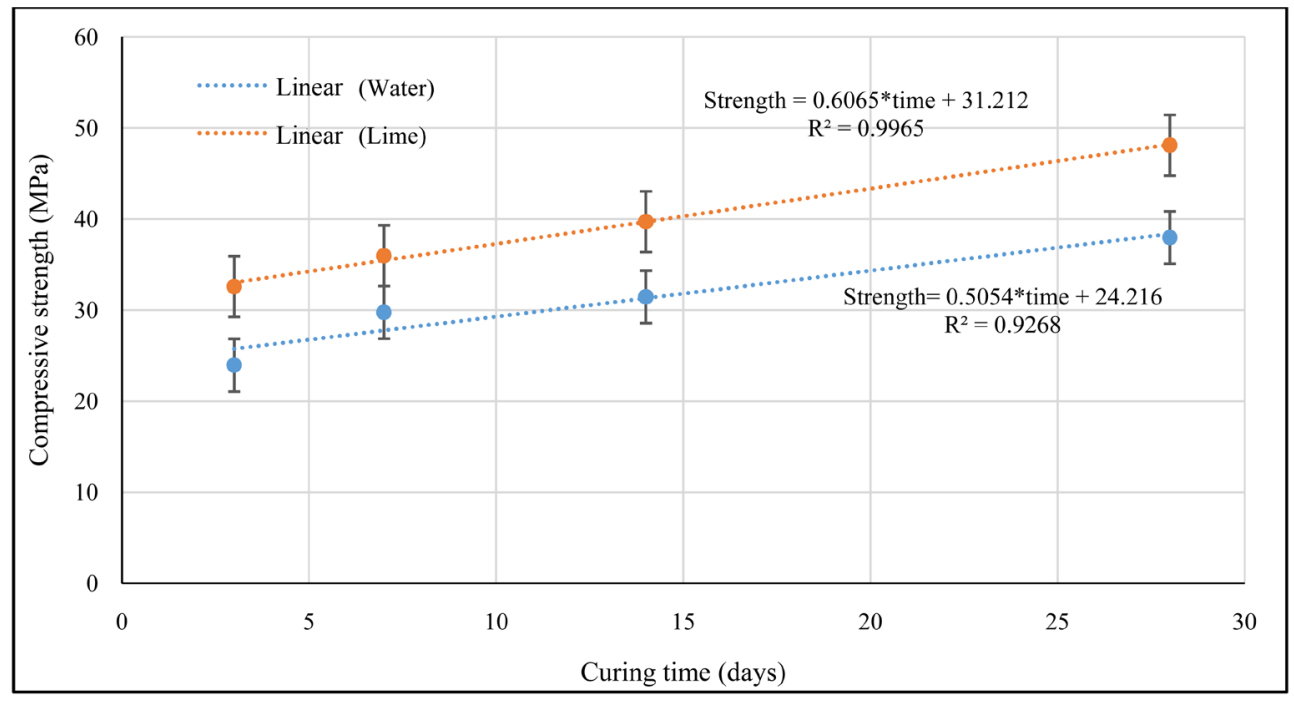

Figure 2. PWCB mortar mix cured in water and lime saturated water. 
Table 4. ANOVA for CONT cured in water and lime saturated water.

\begin{tabular}{ccccccc}
\hline Source of variation & SS & df & MS & F & P-value & F crit \\
\hline Rows & 18.16338048 & 1 & 18.16338048 & 4.10447034 & 0.13587373 & 10.12796449 \\
Columns & 150.3763291 & 3 & 50.12544303 & 11.3270982 & 0.038255638 & 9.276628153 \\
Error & 13.27580344 & 3 & 4.425267813 & & & \\
Total & 181.815513 & 7 & & & & \\
\hline
\end{tabular}

NB-SS: sum of squares, df: degree of freedom, MS: Mean Square value.

Table 5. ANOVA for PWCB cured in water and lime saturated environment.

\begin{tabular}{ccccccc}
\hline Source of variation & SS & df & MS & F & P-value & F crit \\
\hline Rows & 137.5939829 & 1 & 137.5939829 & 106.293888 & 0.001946219 & 10.12796449 \\
Columns & 229.5744464 & 3 & 76.52481548 & 59.1168305 & 0.003623895 & 9.276628153 \\
Error & 3.883402485 & 3 & 1.294467495 & & & \\
Total & 371.0518318 & 7 & & & & \\
\hline
\end{tabular}

NB-SS: sum of squares, df: degree of freedom, MS: Mean Square value.

cement extenders affects the chemistry of Portland cement when compared to Portland cement alone and the blends are much more sensitive to the particular curing condition. The reasons provided for the lower strength of mortar specimens in water curing than lime saturated curing is not different from that of the explanations given for the trend of CONT mortars. The decrease in $\mathrm{Ca}^{2+}$ ions in water curing environment does not favor pozzolanic reaction hence reduce strength of cement products.

The ANOVA test indicated in Table 4 and Table 5 rejected the research hypothesis however accepted the alternative that curing environment affects strength development of CONT and PWCB mortars.

\section{Conclusions and Recommendations}

Curing conditions are fundamental to mortar and concrete performance. The best practice for laboratory water curing is to add calcium hydroxide to solution to prevent leaching from the sample. However, in many countries samples are cured in tap water. Since the concentration of Ca ions in the tap water is low and CH is quite soluble in cementitious materials, substantial leaching occurs which results in significantly lower compressive strengths. To counter these lower compressive strengths the resulting mixtures unnecessarily contain higher cementitious material contents. This results in higher costs and greater environmental burden. To illustrate the point, this study cured both straight Portland cement and mortar containing 30\% replacement for ground waste brick in solutions of either tap water or water containing the $30 \%$ replacement for ground waste brick in solutions of either tap water or water containing the ASTM C511 [26] recommended dosage of $\mathrm{CH}$.

Combining the overall results and the discussions made on this study, it is concluded that curing environment and curing times are important parameters that affect compressive strength of concrete or mortars. The lime curing environment produced higher strength at later ages for the straight cement mixture and all ages for the mixture containing a pozzolan. The strength difference can be directly attributed to calcium hydroxide leaching which was demonstrated by $\mathrm{pH}$ testing of curing solution.

Our recommendations are that any samples cured for strength testing should be cured in lime water. It is unsuitable to cure these materials in tap water and current techniques in Ghana and other African countries WHICH artificially results in low compressive strength.

\section{References}

[1] Sharp, J.H. (2006) Surely We Know All about Cement-Don’t We? Advances in Applied Ceramic, 105, 162-174. http://dx.doi.org/10.1179/174367606X115904

[2] Global Cement Report (2014) International Cement Review. http://www.cement.com 
[3] Vigil de la Villa, R., Fernandez, R., Rodrıguez, O., Garcıa, R., Villar-Cocina, E. and Frıas, M. (2013) Evolution of the Pozzolanic Activity of a Thermally Treated Zeolite. Journal of Materials Science, 48, 3213-3224. http://dx.doi.org/10.1007/s10853-012-7101-z

[4] Sabir, B.B., Wild, S. and Bai, J. (2001) Metakaolin and Calcined Clays as Pozzolans for Concrete: A Review. Cement and Concrete Composites, 23, 441-454. http://dx.doi.org/10.1016/S0958-9465(00)00092-5

[5] Tironi, A., Terezza, M.A., Scian, A.N. and Irassar, E.F. (2013) Assessment of Pozzolanic Activity of Different Calcined Clays. Cement \& Concrete Composites, 37, 319-327. http://dx.doi.org/10.1016/j.cemconcomp.2013.01.002

[6] Agarwal, S.K. (2006) Pozzolanic Activity of Various Siliceous Materials. Cement and Concrete Research, 36, 1735-1739. http://dx.doi.org/10.1016/j.cemconres.2004.06.025

[7] Bediako, M., Gawu, S.K.Y. and Adjaottor, A.A. (2012) Suitability of Some Ghanaian Mineral Admixtures for Masonry Mortar Formulation. Construction and Building Materials, 29, 667-671. http://dx.doi.org/10.1016/j.conbuildmat.2011.06.016

[8] Samet, B., Mnif, T. and Chaaboni, M. (2007) Use of Kaolinitic Clay as a Pozzolanic Material for Cements: Formulation of Blended Cement. Cement and Concrete Composite, 29, 741-749.

[9] Toledo Filho, R.D., Gonclaves, J.P., Americano, B.B. and Fairbairn, E.M.R. (2007) Potential for Use of Crushed Waste Calcined Clay Brick as Supplementary Cementitious Material in Brazil. Cement and Concrete Research, 37, 1357-1365. http://dx.doi.org/10.1016/j.cemconres.2007.06.005

[10] Bediako, M. (2014) Laboratory Curing of Cement Based Products: The Perceptions of the Building Professionals. CSIR-BRRI Unpublished Technical Report.

[11] ASTM (2014) Standard Practice for Making and Curing Concrete Test Specimens in the Laboratory. C192-14, ASTM International, West Conshohocken.

[12] Irish Concrete Society (2004) The New Concrete Standards. Irish Concrete Society Publishers.

[13] Kosmatka, S.H. and Wilson, M.L. (2002) Design and Control of Concrete Mixtures. Portland Cement Association, Skokie.

[14] Mamlouk, M.S. and Zaniewski, J.P. (2006) Materials for Civil and Construction Engineers. Prentice Hall Publishers, Upper Saddle River.

[15] Bullard, J.W., Jennings, H.M., Livingston, R.A., Nonat, A., Scherer, G.W., Schweitzer, J.S., Scrivener, K.L. and Thomas, J.J. (2011) Mechanisms of Cement Hydration. Cement and Concrete Research, 41, 1208-1223. http://dx.doi.org/10.1016/j.cemconres.2010.09.011

[16] Neville, A.M. (1996) Properties of Concrete. 4th Edition, ELBS, United Kingdom.

[17] Ballester, P., Hidalgo, A., Mármol, I., Morales, J. and Sánchez, L. (2009) Effect of Brief Heat-Curing on Microstructure and Mechanical Properties in Fresh Cement Based Mortars. Cement and Concrete Research, 39, 573-579. http://dx.doi.org/10.1016/j.cemconres.2009.04.002

[18] Lothenbach, B., Winnefeld, F., Alder, C., Wieland, E. and Lunk, P. (2007) Effect of Temperature on the Pore Solution, Microstructure and Hydration Products of Portland Cement Pastes. Cement and Concrete Research, 37, 483-491. http://dx.doi.org/10.1016/j.cemconres.2006.11.016

[19] ASTM (2012) Standard Practice for Making and Curing Concrete Test Specimens in the Field. C31, ASTM International, West Conshohocken.

[20] Zemajtis, J.Z. (2014) Role of Concrete Curing. Portland Cement Association, Skokie.

[21] ASTM (2006) Standard Specification for Standard Sand. ASTM international, C778-13, West Conshohocken.

[22] ASTM (2012) Standard Specification for Coal Fly Ash and Raw or Calcined Natural Pozzolana for Use in Concrete. ASTM International, C618, West Conshohocken.

[23] ASTM (2007) Standard Test Method for Compressive Strength of Hydraulic Cement Mortars (2-in or [50 mm] Cube Specimen). C109-03, ASTM International, West Conshohocken.

[24] ASTM (2007) Standard Test Method for Flow of Hydraulic Cement Mortar. ASTM International, C1437, West Conshohocken.

[25] Weng, T.L. and Cheng, A. (2013) Influence of Curing Environment on Concrete with Crystalline Admixture. Monatshefte für Chemie-Chemical Monthly, 145, 195-200.

[26] ASTM (2013) Standard Specification for Mixing Rooms, Moist Cabinets, Moist Rooms, and Water Storage Tanks Used in the Testing of Hydraulic Cements and Concretes. ASTM International, C511, West Conshohocken. 
Scientific Research Publishing (SCIRP) is one of the largest Open Access journal publishers. It is currently publishing more than 200 open access, online, peer-reviewed journals covering a wide range of academic disciplines. SCIRP serves the worldwide academic communities and contributes to the progress and application of science with its publication.

Other selected journals from SCIRP are listed as below. Submit your manuscript to us via either submit@scirp.org or Online Submission Portal.
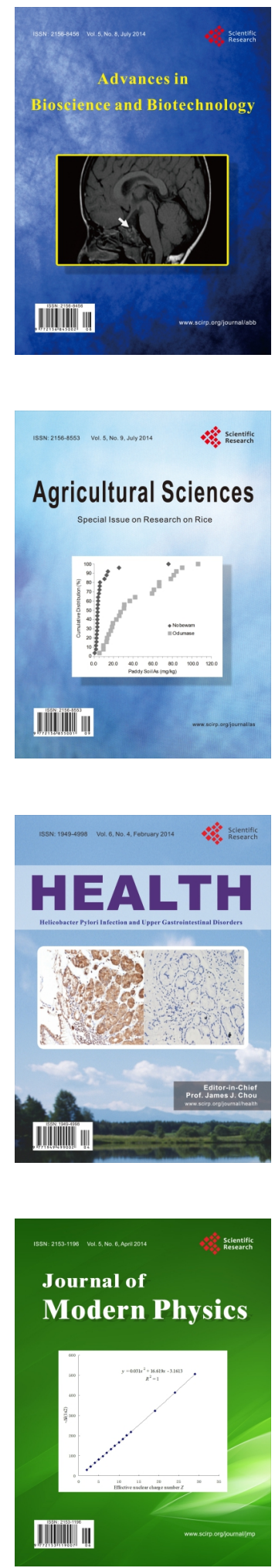
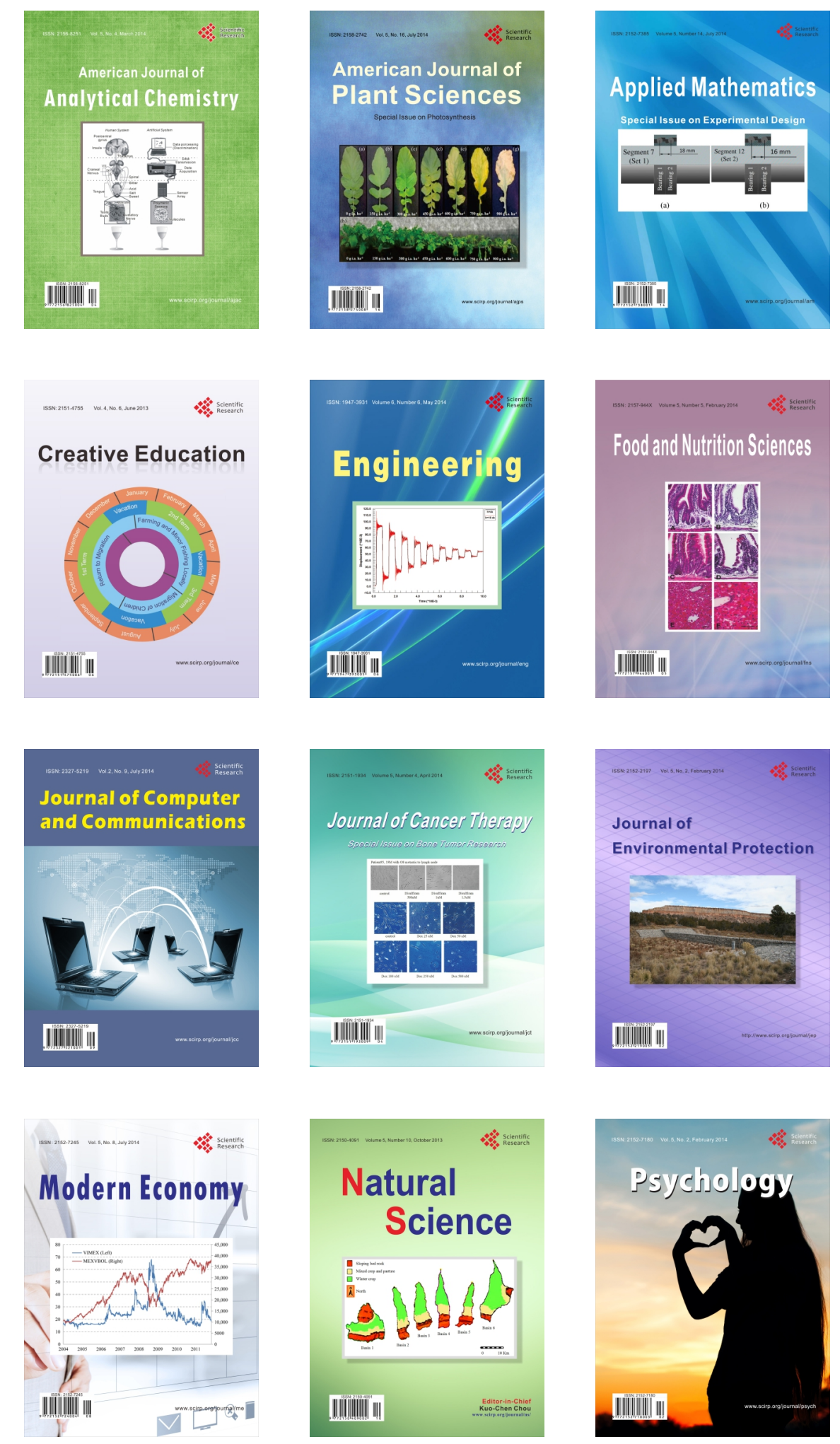